\title{
Managing Exceptionally
}

Author(s): Henry Mintzberg

Source: Organization Science, Vol. 12, No. 6 (Nov. - Dec., 2001), pp. 759-771

Published by: INFORMS

Stable URL: http://www.jstor.org/stable/3086046

Accessed: 04/01/2010 11:14

Your use of the JSTOR archive indicates your acceptance of JSTOR's Terms and Conditions of Use, available at http://www.jstor.org/page/info/about/policies/terms.jsp. JSTOR's Terms and Conditions of Use provides, in part, that unless you have obtained prior permission, you may not download an entire issue of a journal or multiple copies of articles, and you may use content in the JSTOR archive only for your personal, non-commercial use.

Please contact the publisher regarding any further use of this work. Publisher contact information may be obtained at http://www.jstor.org/action/showPublisher?publisherCode=informs.

Each copy of any part of a JSTOR transmission must contain the same copyright notice that appears on the screen or printed page of such transmission.

JSTOR is a not-for-profit service that helps scholars, researchers, and students discover, use, and build upon a wide range of content in a trusted digital archive. We use information technology and tools to increase productivity and facilitate new forms of scholarship. For more information about JSTOR, please contact support@jstor.org. 


\title{
Managing Exceptionally
}

\author{
Henry Mintzberg \\ McGill University, 1001 Sherbrooke West, Montreal, Canada H3A IG5 \\ mintzber@management.mcgill.ca
}

\begin{abstract}
This paper is about two managers of Red Cross refugee camps in Tanzania who manage by exception in rather exceptional circumstances. Using a model of managerial work that delineates roles carried out at the information, people, and action levels, inside and outside the unit, these managers' activities concentrate especially on communicating and controlling a chaotic situation in a steady state, at least temporarily. While many other managers appear to be moving away from conventional forms of managing - to more linking instead of leading and convincing instead of controlling, etc.-here are two managers who seem to be going the other way, precisely because their situation is so unconventionally risky. Ned Bowman's great contribution has been not just about risks and options per se, but in the risks that he himself took and the options that he himself exposed. In this spirit, the paper concludes with a plea for the opening up not simply of content, but of context.

(Managing; NGO; Leadership; Management by Exception)
\end{abstract}

This paper is about managers and the risks that some of them have to take in situations where there may be no real options-managers, risks, and options rarely encountered in the management literature. In the words of one review of this paper, these are "circumstances that few managers can imagine."

This paper probes into managing by exception, on behalf of an exceptional organization that works in exceptional circumstances. The research took place on a visit to the Red Cross activities in N'gara, Tanzania, in October of 1996, where the organisation ran two refugee camps-Benaco, with 175,000 Rwandans, and Lukole, with 20,000 Burundians. There, the head of the subdelegation, Abbas Gullet, was observed for one day, followed on the next day by the operating manager for the two camps, Stephen Omollo. As Karl Weick (1974) has pointed out, interesting things can be revealed by studying unusual organizations.

\section{The Model}

This study forms part of a larger research project in which 29 managers in a wide variety of circumstances have been observed for a day each-managers in health care, government, business, and various not-for-profit organizations-from the front country manager in a federal mountain park to the chief executive of Canada's largest bank. Such a short time of observation is not meant to provide definitive conclusions about each of these people and their jobs: the sample should be seen as one of 29 managerial days rather than 29 management jobs. The intention has been to uncover the variety of circumstances and styles exhibited in the conduct of managerial work. The circumstances and styles of the two managers in question here do, however, deserve to be singled out because of the unusual nature of the setting.

Articles in the research literature are appropriately judged by their contribution to our conceptual understanding. The contention here is that their contribution to our contextual understanding-such as the very particular circumstances described in this article-sometimes merits attention as well. In a literature that tends to be Western, and especially American, about business and especially about big business, we need to open up context alongside content.

This research program began with the assumption that we know what managers do but are less clear on the variety of ways in which they do it. So the literature delineating managerial roles was reviewed to weave these into an integrative framework. Almost all these publications (including those of the undersigned) were seen as lists rather than real models. The need was to integrate these into some sort of comprehensive model. The one used here is shown in Figure 1 (see Mintzberg 1994).

At the center sits the person who comes to the job, with his or her thoughts and feelings about the work, and specifically some sort of frame by which to carry it out. This in turn leads to an agenda of specific issues and work schedules. All this can be thought to constitute the basic core of the job of managing, as suggested by its placement in the center of the figure.

Surrounding the core are three concentric circles that represent three levels through which managerial work can take place: labelled information, people, and action. From the inside out, beginning with the most abstract level, a 


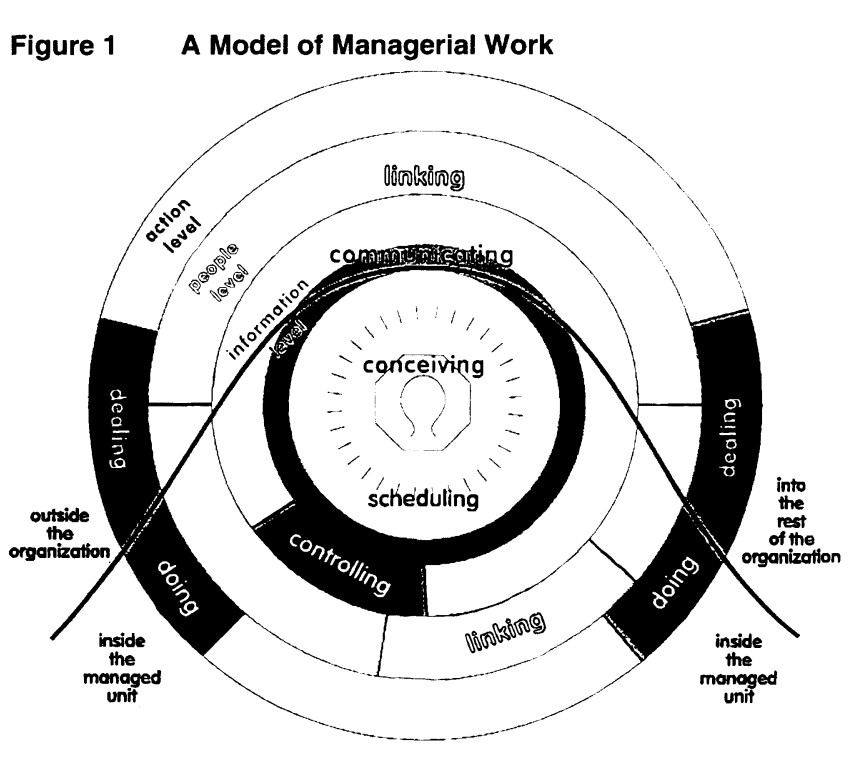

manager can process information, in the hope that this will drive people to take action. More tangibly, a manager can work with people to encourage them to take action. And at the most concrete level, a manager can manage action more or less directly. This is not to argue that managerial work is so partitioned. Especially when effectively executed, activities tend to blend together across these levels. But the distinctions appear to be useful for conceptual purposes, and so too in practice managers will often tilt in a given activity toward one level or another.

In each case, as shown, the managerial effort can be directed inside the unit being managed, or outside it, to the rest of the organization or to its external environment. This leads to six roles in the three circles: two at the information level, two at the people level, and two at the action level. They are as follows:

Communicating: Seeking and receiving information as well as sharing it with others, whether internally as disseminator or externally as spokesperson.

Controlling: Using information to control the work of insiders, whether by issuing directives, designing structures, or developing and applying systems and procedures.

Leading: Encouraging and enabling people within the unit managed to take effective action, whether by focusing on the individual (as in mentoring and rewarding), the group (as in team building and conflict resolving), or the entire unit (as in culture building).

Linking: Relating to people outside the unit by establishing a network of contacts and using it to represent the needs of the unit as well as to transmit its influence to people externally, also to receive influencing efforts transmitted to the unit from these people.
Doing: Supervising the taking of internal action more or less directly, including directing projects for change and handling disturbances and crises.

Dealing: Engaging in negotiations and executing agreements ("doing deals") with outsiders.

While virtually all managers can be described as engaging in all these roles, just as clearly will many favour one level (information, people, or action), one orientation (internal or external), even one role, or perhaps a particular blending of several. And how each of these roles is played, alone and in conjunction with the others, will vary from one manager to another.

To study this, the research here has proceeded in a rather simple way. A variety of managers have been observed from the time they began their work in the morning until they finished it at the end of the day. Notes were taken of all activities observed, alongside records of the time of starting and ending. Documents were also collected when appropriate. Lulls in the work-travel in automobiles, for example-as well as quiet time at the end of the day was used to ask questions, clarify activities confusing to the observer, and probe into the managers' feelings, attitudes, and conception of the work and the job. Time was also taken to discuss the job in its broader context, often including review of agendas over the course of the last month to compare the day with others and uncover a wider variety of scheduled activities performed. Later, the activities of the day were written up and then studied, particularly (but not only) in terms of the model, to draw conclusions. The full draft report was then checked for accuracy by the manager, who often included comments on the conceptual interpretation.

\section{The Setting}

In total, 700,000 people populated the six refugee camps in the area of N'gara, Tanzania in October of 1996. The International Federation of Red Cross and Red Crescent Societies, as it is officially titled, played a role in all these activities from the beginning in 1993, setting up two other camps besides the two it ran, and generally working closely with the other NGOs. (This stands for nongovernment organization, but these are as much NBOs-nonbusiness organization-as they are nongovernment. They might better be called NOOs-nonowned organizations. See Mintzberg 1996.) There were at one point 150 NGOs on site; by October of 1996, they numbered 15. Running a camp means running a municipality and more, including food distribution, sanitation, road construction and maintenance, housing, and health care.

The Red Cross is the world's oldest and largest humanitarian aid organisation, with a worldwide budget of 
$\$ 20$ billion and a full-time employment of 280,000 , as well as 150 million volunteers, plus 250 people in its Geneva headquarters who deal with relief operation and development work. The Federation comprises over 170 national societies. In its "delegations," members of the local society often work alongside Federation "delegates." In N'gara, the Tanzanian Red Cross Society (TRCS) supplied local workers as well as one "counterpart" to each the Federation's delegates, for training. The operation in October of 1996 under Abbas Gullet's responsibility included 17 Federation delegates (from Germany, Norway, Canada, England, the United States, New Zealand, Russia, and Kenya-the original home of both Abbas and Stephen), 516 full-time people from the TRCS, and 1,500 paid part-time workers from the camps.

Delegates, on contract and dependent mostly on the small, twice weekly Red Cross flights for connections to the outside, turned over rapidly. At 11 months, Abbas was the most long standing. They lived in a "compound" that was pleasantly but modestly appointed. (Each delegate had a small room, lined up in motel-like fashion, and a common hot shower had just replaced the use of buckets.) In a sense, this was what Goffman (1961) has called "a total institution": the delegates lived, ate, socialised, and (in or nearby) worked there. The weather, at 1,800 meters altitude, was pleasant, in surroundings that were beautiful, and belied the butchery that had recently taken place just on the other side of the borders of both Rwanda and Burundi. On one particular day in April 1994, 250,000 people crossed from Rwanda, which Abbas thought to have been to then the largest cross-border movement of refugees anywhere ever. The German Red Cross Society had water available for them in 18 hours. ${ }^{1}$

The compound was fenced and guarded, but not with firearms. To enforce the Red Cross's strict neutrality, signs were installed on all its vehicles and compound gates showing a machine gun with a red slash through it. But that did not always work: Some months earlier, a band of drunk refugees and Tanzanians invaded the compound, held some of the delegates (including Stephen) at gunpoint, and shot up some doors and locks before they found some money and left.

One part of the compound contained the administrative area, where the offices (plus telecommunication equipment) were laid out in a quadrangle, with labels such Radio Room, Security, Relief (which included Stephen's desk), Logistics, Transport, Health Department, and Head of Subdelegation (Abbas' office).

Abbas has spent most of his life in the Red Cross, including as a youth volunteer who made trips to Germany, Britain, and later Canada. He had been with the Federation for six years, including a recent stint at the Geneva headquarters. Stephen joined the delegation from Ireland, where he makes his home.

\section{October 1996, with Abbas Gullet, Head of Subdelegation}

The day began with breakfast at 7:25 a.m., then a short walk to the office, where Abbas looked through the new "pactors" on his desk, printed correspondence much like Telex. These concerned an invoice, a shipment of material, and a report to be sent. He then turned to his computer to prepare his weekly news report to the Desk Office in the Geneva headquarters. Several people came in for the daily meeting of his key direct reports at 7:45 a.m.: Gier, a Norwegian in charge of Health; Georges, a Canadian in charge of Finance and Administration; Sasha, a Russian in Logistics; and Stephen on Relief.

They went around the table, with Sasha talking about available vehicles and requests for them and Georges mentioning that the budget was completed. Mostly, the discussion revolved around Abbas, who had to explain many of the details ("Who to sign?", "Where does this form go?"). Gier and Georges were relatively new, while Sasha and Stephen were sitting in for their bosses, who were away.

When his turn came, Abbas briefed the others on a "workshop" on "camp management" that was taking place in the Tanzanian compound to share experiences among the East African Red Cross Societies of Tanzania, Kenya, Uganda, Ethiopia, Sudan, and Eretria. An American named Bill and a Mexican named Juan were also attending on behalf of the Federation. Abbas explained why he was reluctant to release his staff for three days to attend, because of work pressures, and warned Sasha to be careful about excessive demands on the cars (a carefully guarded resource in N'gara).

Then Abbas told of staffing news, including replacements that had been approved. There was no news yet about replacements for himself, Stephen, and Frank (Stephen's boss in Relief), whose assignments were coming to an end. Abbas also explained the "tougher stance" of the Tanzanian government concerning the fourkilometer ring it had recently placed around the camps. (The refugees were free to move about, for example to work the land assigned to them, trade in the local markets, and forage for firewood-no fuel was provided for cooking, although the area was barely forested. But now, officially at least, they were not allowed beyond four kilometers, although how this was to be defined, let alone enforced, was not clear.) Then Abbas turned to Stephen and said, "You just need to put your ear to the ground 
Stephen, and find out more about what the feelings are among the refugees."

The meeting ended at 8:13 a.m., and Abbas went back to work on his report for the Geneva desk, with many people coming and going. The report was sent by 8:30 a.m. and then, after discussing problems about a photocopying machine, Abbas walked over to the much larger Tanzanian compound next door for the opening of the workshop. He formally welcomed the participants to the area and explained a bit of the recent history. After the huge movement, things had now settled down. But with the current tensions in Burundi, the Red Cross was ready to act quickly again, and had a "contingency plan," which it updated every three months. After about 10 minutes, Abbas turned the meeting over to Juan, and with a "We go back to business" to me, headed out.

Business was in Benaco. Abbas's car was waiting outside the hall, and it took us to the food distribution area at 9:55 a.m. Refugee porters were milling about, awaiting the arrival of United Nations World Food Program (UNWFP) trucks, which were apparently late. Abbas went into the "stores"-large plastic sheet buildings that were almost empty (except for "balances")-where he inquired about the "rat problem" ("still a problem," he was told) and other details.

As the trucks arrived, the food, in 50-kg sacks, was carried directly to the "chutes" -19 covered areas in allfor its weekly distribution to "team leaders," who in turn distributed it to their "family group" waiting behind a fence in large numbers. But today Abbas found the system too efficient, because the food was supposed to go into the stores first for counting and control, before going into the chutes. So he raised a number of questions about this with the woman who managed the food distribution, also about the fact that the staff were not wearing Red Cross bibs. They had to be clearly identified, Abbas insisted, and he encouraged her to have regular meetings with her staff.

Abbas also chatted with a woman from the UNWFP about the food distribution and problems they were having with a contractor. At her request ("maybe they will listen to you"), he promised to speak to the UN people. We then walked past one of the chutes and through a gate, where the many people milling about opened up a space for us to pass into an open area of the camp. (This was obviously the most animated area of the camp, followed perhaps by the market area, where fresh food, grown or bartered beyond the gates, was sold alongside a surprising array of other things.)

After walking around, we returned to the car and drove to another area of the camp, where Abbas pointed out the living arrangements: rows of small houses off a large central road, with rows of latrines on one side of the houses and of cooking facilities (two to a household) on the other. Earlier seen from a distance, this camp looked vast. But close up, away from the food distribution gates, it did not seem crowded, neither here nor in the market area, playing fields, or school yard. We left the camp, and after a brief visit to the water treatment facility that served the compound, we were back in Abbas's office at 12:30 p.m.

There was the usual chatting with people going past and a look at a few pactors that had arrived, one from someone needing a new passport and another concerning hotel bookings, and a third from the Logistics coordinator about the possibility of getting some oil tanks from an Italian company that was leaving the area, if Abbas could act soon. Sasha happened to drop by just then, and Abbas charged him with checking out the tanks.

A succession of people and pactors followed (about flight bookings, budgets, pay rates, and a broken machine part), and then Abbas joined several people at lunch, at about 1:00 p.m. Hans, from the workshops, asked Abbas if he could help him secure some needed generators, and Bill went over the plans for the workshop, seeking Abbas's approval on the participation of his people. "It's okay with me. Just tell them to talk slowly, clearly." At 1:30 p.m., he took a break to rest, and returned to the office at 2:00 p.m.

Gier came in then with "a number of small concerns and a few big ones": do refugees working for the Red Cross have five-day weeks; are there evacuation plans for Benaco; did Abbas plan a salary increase for "the professor" (a Rwandan refugee academic who was working on software for health monitoring); what about drainage and the installation of night lighting for the "Gulf Hotel"their nickname for the hospital. Abbas explained various things carefully to Gier, who had only been there one month. He took a stand on a few of these issues, especially concerning expenditures, but mostly sought Gier's opinion and encouraged him to decide.

The biggest issue concerned the matron (head nurse) at the hospital. She had upset the Tanzanian staff for a variety of reasons, and they wanted her out. Gier also reported an apparent lack of "counterpartism" in the hospital. He offered a short list of candidates, one of whom was not the assistant matron, whom Gier said was also apparently on his way out. Abbas told Gier what he knew of the situation (which seemed to be considerable), including the fact that it had been a problem since he had arrived 11 months earlier. Abbas suggested that because the matron had been in her job for 18 months they could simply view this as a normal rotation, and she could keep her job as a nurse. 
At 2:34 p.m., with "Okay, now for my side," Abbas raised several other issues. There was the question of the production of concrete slabs for the latrines in Benaco, which had fallen behind plan, and they discussed how to increase the rate. Gier commented on the state of sanitation in the camp, which he called remarkable: "There is a lack of smell, a lack of flies, a lack of garbage all over." Diarrhea was not a major problem, but more water would have helped, at which point Abbas discussed difficulties in dealing with the United Nations people. They noted an increase in skin disease in one camp, and Abbas wondered if soap was being pilfered and sold.

They then came back to the Gulf Hotel, touching briefly on medical staffing, including whether or not to hire an anesthetist. (Nurses were doing the job.) They discussed costs, especially the large expenditures on drugs and the possibilities of pilferage, also a problem with a driver for the hospital who apparently tried to bribe a security officer. Abbas told Gier that the wrong person had been fired in this circumstance, and the decision had to be reversed. Gier left at 3:18 p.m.

Sasha was waiting outside and came in, concerning several issues: vehicles arriving from Doctors Without Borders Holland, stocking fuel where it could not be pilfered, and "not so good news-an engine went kaput." Abbas asked him to check if the engine had been overhauled. Sasha went out at 3:42 p.m. to find a memo, and Abbas, seeing some people walk by carrying pillows, went out quickly and spoke to them. He was concerned about pilfering, but it turned out they were acting at the request of the workshop people. Abbas nonetheless asked the man who looked after the compound area to ensure they had the right gate passes. Then Sasha reappeared with the memo about a request for vehicles for the workshops, to which Abbas replied "no way." He also explained how to charge the fuel costs to the workshop. Sasha left at 3:47 p.m.

From here, with no more scheduled meetings for the day, pactors and other messages were reviewed, concerning electronic equipment, chlorine tablets not available in the desired size, flight arrangements for outgoing personnel, news of new delegates cleared for posts here, a visit from a Bonn desk officer, and a note from the TRCS office in Dar-es-Salaam advising of a physician who would be flying in for a job interview. At 4:17 p.m., Gier walked by and Abbas asked him about the physician's visit: Had Gier or anyone else proposed this? The writer of that message had apparently not even checked with Abbas's direct report in Dar-es-Salaam. "I will be nasty with him-hope I won't get into trouble!"

At 4:25 p.m., Abbas began work on a "midterm" written evaluation of a delegate, but with the comings and goings picking up in frequency as well as intensity, he was not going to finish this today. Felicitus, who ran the Gulf Hospital on behalf of the German Red Cross, dropped off a memo stapled closed, which Abbas, luckily, happened to open and read immediately. He discovered that a new assistant matron as well as a new matron were to be selected. He called her and Gier back into his office

"Why do you want to move the Assistant Matron out of the hospital?" he asked Felicitus. Gier, unaware of what Felicitus had written, said "No, there's no rush on this one," but Felicitus said, "He will not be accepted as the Matron." Apparently there was some sort of misunderstanding between them. Then Abbas, in his most forceful tone of the day, said he knew the man, also named Stephen, well, that he was an excellent person, and that "I will protect him as long as I am here." Felicitus left, looking dejected, and so Abbas added, "unless you have already told him." Felicitus was back in a flash. "I have." (She had apparently misinterpreted something Gier said earlier as meaning she should remove him. Between the vague signals and different thoughts of the various people involved, both delegates and Tanzanians, this situation had somehow mushroomed into a major confusion.)

Abbas offered to speak to the Assistant Matron to help resolve the confusion, and Felicitus, obviously relieved (and expressing the fact that she, too, appreciated that person), said, "I wish you could do that." So it was agreed that Abbas would try to work it all out the next day. Indeed, they ended up agreeing that Stephen would be promoted to "Acting Matron!" "Why not Matron?" Felicitus asked, and Abbas said, "One step at a time." He wanted to speak to his own counterpart (who was away) first.

Then Abbas, commenting on how he liked this quiet time at the end of the day to get some work done, turned back to his computer and the midterm report. He barely hit one key when the telephone rang from Nairobi about flight arrangements. That call lasted 20 minutes, after which Sasha poked his head in to report on the trucks that had been offered. They started to get into the issue when, at 6:00 p.m., Felicitus put her head in with the comment: "Stephen is here!"

So Abbas sat down at his table with Stephen, the Assistant Matron, who looked concerned. "How is your hospital these days?" Abbas asked, and they discussed a small outbreak of meningitis, among other things. "Is there any special reason to say you are exhausted, overworked?" Abbas asked, and Stephen said no. He did express concern about Felicitus's upcoming departure and the absence of a replacement, and Abbas urged "you guys" to be more proactive. He continued to probe on 
administrative arrangements at the hospital, and the role of the Tanzanian staff.

Then Abbas turned to the issue at hand, to clarify Stephen's letter of appointment and understand exactly what Felicitus had told him. Stephen said that he understood he would no longer be Assistant Matron, but not that he would lose his job; he hoped to go back to his old nursing position. Meanwhile, Stephen said he had helped Felicitus to draw up the list of names for possible new Matron and Deputy Matron. They reviewed the names. When Abbas asked about the problem of management in the hospital, Stephen looked very uncomfortable, and Abbas proposed they talk in Swahili. (It is the common language of both Kenya and Tanzania, with English the second. Both countries are former British colonies. In contrast, Swahili is less widely spoken in Burundi and Rwanda, both of which, as former French colonies, had that as their second language.) Even so-as Abbas reported to me afterward-Stephen was hesitant to discuss the concerns about the Matron, although later (back in English), Abbas urged him to be more forthcoming with Felicitus on these issues. "If you're not giving her the information, what's she to do?"

Clarifying what Stephen had been told, and who else had been told what, Abbas said: "I'll suggest that you keep your old post as Deputy Matron and prepare for you to act as Matron . . . But you need to be up front with Felicitus. We know stuff is going on at the hospital-the driver who tried to bribe someone is being fired." Stephen said he understood. Abbas asked, "What else do you have?" Answering "Actually nothing," a very relieved Stephen left a very relieved Abbas at 6:44 p.m., Abbas's day, aside from an evening party for one of the departing delegates, ended there.

\section{October 1996, with Stephen Omollo, Red Cross Camp Manager, Benaco and Lukole}

This day began almost like the last, but from a different perspective. At 7:45 a.m., Stephen joined the daily coordinators meeting in Abbas' office. They went around, as the day before. Stephen followed Gier and reported that six accused bandits had been arrested at one of the camps and three more were still at large. He asked Gier about an illness in the hospital and Abbas asked Stephen about the source of some meningitis in the camp. Stephen also reported about the state of food distribution in the camps, and on a meeting of refugee team leaders and some concerns they had about the camp management.

At this point, Abbas complained about the bib situation of the day before. "I hope you'll give instructions this morning that everybody wear identification." He also expressed concern about the food going straight into the chutes and implored Stephen to "get answers" on this. The go-around continued, to Sasha, Georges, and Abbas, and the meeting ended at 8:06 a.m.

Stephen then went into the office called "Relief," where he met his own staff, all from the Tanzanian Red Cross Society, including his two counterparts-Geoffrey, in charge of Benaco, and Kibari, in charge of Lukole. This was a daily meeting, corresponding to and following that of Abbas.

They discussed a problem of road maintenance (including speed bumps that were too high), digging pits for the latrines, the chute problem, and the meningitis cases at Benaco, among other things, with Stephen doing some briefing but mostly the two camp managers talking. The man in charge of construction joined the meeting and raised a problem with the plastic sheeting, also commenting that "The situation in the construction unit is pretty bad... We have no materials." Stephen said he would take up both issues with others, and then raised the problem of the bibs, briefing them on Abbas's concern. They discussed how many bibs they had and how many they would have to order. The availability of vehicles was the next issue, which Stephen believed required "a polite discussion with Sasha."

The meeting ended at 8:52 a.m., and a few minutes later the group of them marched across the quadrangle into the Logistics office to discuss the need to order bibs, one of them commenting at one point about "Logistics always promising." At this point, there were eight people in this small office, all in on the conversation, while the communications radio was going incessantly. Then Stephen, Geoffrey, and Kibari headed to the Transport office to meet Sasha. They explained their problem while he looked at his screen to see what was available. Sasha concluded that "without specification, I will not sign," and they left.

Discussion continued in the Relief office, with people coming and going, while Stephen took any spare time to fill in some administrative forms at his desk. He had commented earlier that normally he would be in the camps by this hour, but a special 10:00 a.m. meeting was keeping him here today.

At 9:52 a.m., Abbas put his head in, and they went over to his office. Their discussion concerned the "management style" at Lukole and some concerns about it being "very tough on" the refugees. Stephen told Abbas of a meeting he called for Saturday of refugee community leaders, to sort the problems out, and of an official complaint filed lodged with the UNWFP. "Why didn't they write to you?" Abbas wanted to know, and Stephen said 
that when the refugees are not happy with the Red Cross, they write to the UN and vice versa. Abbas was concerned: He wanted to see a copy of the letter and to ensure that Stephen was pursuing the matter vigorously.

Abbas wondered why Geoffrey was still in the compound and not at the camp, and Stephen explained the problem of transport. "It's 10 o'clock," Abbas shot back. "He's meant to be a camp manager; he's sitting there, the distribution is going on; I need feedback immediately. I want the guy out of here as soon as possible." Abbas also felt that Geoffrey should have been tougher about keeping his car, and he expressed concerns about hiring procedures and some transfers that had taken place: "Don't be taken for a ride." They also discussed plans for Stephen's next assignment, as his posting too was coming to an end.

At 10:08 a.m., Stephen headed back to the Relief office. A few minutes later, his appointment appeared, a fellow named Ben from the European Community Humanitarian Assistance Office (ECHO), one of the main funders of personnel for the Red Cross operation here. Ben had been in this area for two weeks to audit the operation and find out its needs for the coming year. They headed over to the conference room, at 10:15, and were later joined by Geoffrey.

The meeting took place in a tone entirely different from that of the earlier part of the morning. Ben's knowledge of the operations, the detail of the many of his questions, and the conscientiousness with which he pursued his responsibility were impressive indeed. The same could be said of Stephen's responses, which seemed to be highly informed, articulate, and straightforward. This remarkable conversation lasted an hour and a half.

Ben opened with: "What kind of assets do you need to do food distribution in the camp? I have to tell Brussels how effective the NGOs are at that." Stephen explained his job and the coordinating activities, and they went more and more deeply into every aspect of the operation, including procedures, systems, the precise number of people needed, and who, specifically, was doing what, with Stephen, for example, explaining each detail of the steps in the food distribution chain. "So, two days of preparations for four days of distribution?" Ben asked at one point.

"Food monitoring" came in for some discussion, after Stephen said that $98 \%$ of the householders got what they were supposed to get. Ben was suspicious. He wanted to know, "What actually ends up in their stomachs?" as opposed to up for barter or sale, or perhaps "taxed" away. "That, for me, is "food basket monitoring,", he said. They discussed biweekly instead of weekly distribution, and construction-how permanent should buildings be, mud bricks or cement bricks, etc. Then Ben launched into the "soft sector," such as the distribution of management duties. Stephen said that the Red Cross tended to end up in the coordinating role among the different NGOs in the area. With a "Gentlemen, that's it. Thank you very much for your time," Ben left at 11:41 a.m. Stephen, Geoffrey, and I then headed off to Benaco in one of the Red Cross vehicles.

Lunch was at Le Petit Mathieu, a restaurant established in the middle of the Benaco camp by an enterprising refugee, with tables set up on the red earth and covered by plastic sheeting. At 12:55 p.m. we headed to the food distribution area. The activity had finished in the morning as it was supposed to, although a number of the refugee porters were still hanging around. Stephen chatted briefly with the warehouse manager, and then left at 1:10 p.m. No problems, Stephen reported to me in the car: "I used to work here from eight until six, when there were all kinds of problems, so if anything was wrong, they would be telling me." In other words, he felt that just his presence was enough to flag difficulties: The refugee workers knew him well enough to let him know.

We arrived at Lukole at 1:33 p.m., a "settlement camp," Steven explained: older, more established, Burundian, and much more spread out. With each family allotted a half acre around its home, usually constructed of red mud bricks, this hardly felt urban, let alone like a refugee camp. Twenty thousand refugees lived in the very spacious area, with areas designated for the market, recreation, schooling, the church, and the dispensary.

We went into the central camp office, a small building with a couple of rooms. Here, Stephen explained his role to me-coordinating the work of the different agencies and dealing with the various camp activities, such as water, food distribution, sanitation, and the health facilities (there was a dispensary on site). On the wall was posted a big sheet called "Lukole Camp Refugee Leadership," which showed a hierarchy of roles. Stephen explained that meetings took place fortnightly for about three hours, including the Red Cross managers and the refugee camp leaders, with other NGO people in attendance. We then headed out on foot at 1:53 p.m.

Stephen said his usual routine, when he arrived earlier, would have been to visit the other NGOs to see if there were any problems. Today, he would have a look at various installations, including the reconstruction of a fence that had been blown over in a recent windstorm.

Stephen was utterly transformed here. He had loosened up during the late morning meeting, and here in the camp he seemed to be totally in his element. As he walked around, Stephen greeted absolutely everyone he passed, smiling and laughing, some in front of their homes, others 
in the streets or in the fields, the men repairing the fence, and people in the public places, such as the market and the dispensary. No few came up to shake his hand and chat, most of whom he seemed to know well. The conversations took place in Swahili and sometimes in English, as well as in what Stephen had learned of the Burundian language.

"My job is to assist and train the local staff," he said. "But there is a need to tour on foot. You need to laugh with the people." Stephen thought that perhaps an absence of that by his counterpart here lay at the root of the concern about "management style."

We arrived back at the central camp office at 2:55 p.m., where Stephen met François, Chairman of the Camp Refugee Committee. They talked at length in Swahili, mostly with Stephen listening, taking notes, and posing the occasional question. François had a list of issues to which he referred. The meeting ended at 3:25 p.m., and Stephen explained to me in the car on the way back that the meeting was about the refugee concern over management style, specifically the bad relations between the refugee committee and the camp manager. Stephen characterized the conversation as "very frank": "I wanted François's views before Saturday's meeting so that I don't float in it."

We were back at the compound at 3:46 p.m. and went into the Relief office, where it was back to the routine of people dropping in followed by paperwork. Stephen had to go over staffing arrangements for the next year, to draw up a plan to be submitted immediately. So with his need to concentrate on that, he suggested my day of observation end there; he would carry on for 45 minutes on the report, to about 4:30 p.m.

\section{The Managerial Roles}

The assessment begins with a review of these two days in terms of the roles of managerial work, introduced earlier, before turning to some of the particular issues of managing in this context.

As noted earlier, all managers generally perform all the roles shown in Figure 1. These two days were no exception to that. But every managerial job has its own circumstances and needs that drive the incumbent to favor some roles over others.

One approach might have been to hypothesize about what the job of managing a refugee camp might look like and then compared this with the findings. But managerial work can be so variable, within these parameters at least, that the researcher preferred to proceed inductively. Each of the roles will be discussed before drawing broader conclusions.

\section{Communicating}

Just as communicating is shown in the model all around the manager, so Abbas and Stephen could be seen gathering information all around their world and likewise sharing it widely with their own staff and with various others. In Abbas's case, this role has to be described as central, perhaps dominant. He was most decidedly the "nerve center" of this operation, with information flowing around him relentlessly. Especially important was his dissemination of information for purposes of training and developing his staff, both delegates and counterparts.

Abbas clearly saw his ability to manage, and so to keep the operations on course, as utterly dependent on his level of information about these operations and especially the currency of this information. So he dug constantly for every scrap of information he could get. And then, in his response to almost every situation that arose over the course of this day, he exhibited a rather remarkable command of the detail.

But Abbas and Stephen seemed to get their information differently: Abbas, in a sense, more verbally, in the compound; Stephen, more visually and viscerally, in the camps. Hard information was clearly present-Abbas could cite all kinds of statistics, as did Stephen in his meeting with the ECHO representative-but soft information about people, events, and operations appeared to be more important. The grapevine was especially active here, although because of language and cultural differences it was not always accurate (as was most evident in the matron issue).

It was delightful to watch Stephen roam through Lukole, picking up information so easily and enthusiastically. Particularly intriguing was his comment about there being no problems in the food distribution area because no one came up to him. This kind of surveillance management takes place not only by "walking about" (Peters and Waterman 1982) but just by "being there."

\section{Controlling (and Convincing)}

The classic view of management first appeared perhaps in the French mines of the last century, where Henry Fayol, as manager, formed his ideas before publishing his famous book of 1916. But it was in the conventional manufacturing of products, such as automobiles, that the concept really flourished. Increasingly, however, Fayol's notions of planning, organizing, coordinating, and controlling (three of which, interestingly enough, can be subsumed under the role called controlling in our model) have been displaced in the literature by ones such as crafting, linking, negotiating, and facilitating. Clearly, both sets of behaviors were evident in the management of this Red Cross delegation in Tanzania. Yet, perhaps of all the 
managers observed to date, none has reflected the classic side better than those here, especially Abbas. Henri Fayol's ideas do remain alive in the refugee camps of N'gara.

To begin, the Red Cross did not lack for systems, procedures, rules, and regulations, some imposed by or for the donor agencies. All organizations, of course, have these, but the Red Cross appears to have them with a vengeance. And hierarchy, that ultimate manifestation of control, was also very much in evidence here, from frequent comments about who had to communicate with whom to that chart on the wall in Lukole showing the levels of "Camp Refugee Leadership."

This control was also reflected in some of the support functions that sat closest to these managers. Finance and Administration was the most obvious but not the only. If Georges policed the expenditures, then Sasha policed the use of vehicles-as noted, a much contested resource.

The use of directives are another manifestation of the controlling role. These, too, were very much in evidence. Abbas was not shy about stating his wishes nor about charging his people with pursuing them, as was clear on a number of occasions during the day. But there seemed to be a particular reason for this. Much of the staff was inexperienced, either being new to management or new to managerial posts in N'gara. Abbas, in contrast, was highly seasoned in Red Cross procedures in general and camp management in particular, plus, at 11 months, he was one of the "old timers" of N'gara. Training was therefore important, and he seemed to spend a great deal of time on it. But the job had to be done, too, and often that meant directing people to do it.

The controlling role was less evident in Stephen's day (except on the receiving end, from Abbas). Perhaps this was just the nature of the day, perhaps it reflected his shorter tenure in the job. Or else, controlling might have diminished in importance as the hierarchy was descended (and it is best to remember that the problem in Lukole was a counterpart management style perceived to be excessively controlling). But this might also have been a reflection of Stephen's own style-more inclined to work in parallel with his people, more at ease in lateral meetings, as with Ben and in his walk through the camp. Steven was probably happier to be in a convincing rather than controlling role, which may have better suited the focused management of the camps themselves, compared with Abbas's need to hold the whole delegation together.

The importance of controlling in Abbas's job is not to imply an absence of convincing, in dealing with insiders no less than with outsiders. This seems to apply especially to his contacts with professionals, such as the health care personnel, as well as to the counterparts in the Tanzanian
Red Cross Society and to the likewise delicate dealings with the refugees in the camps, who are "beneficiaries" in Red Cross terminology, but awfully dependent ones. Here and elsewhere, both Stephen and Abbas had to walk a rather delicate line between controlling and convincing.

\section{Leading}

Managing at the people level-leading internally and linking externally - could be seen on both days, although not nearly to the same degree as the information roles.

Leading appeared in Abbas' activities in three respects. The most significant had to be training and development. At a meeting this observer attended in Europe a few weeks after this experience to discuss management development programs, several representatives of large corporations described their rather elaborate portfolio of training programs. A representative of the Red Cross Federation then described their activities as rather sparse in comparison. But if N'gara is any indication, the Red Cross may well invest far more in management development than almost any other organization. It just takes a different form.

Abbas seemed to be devoting enormous amounts of time to coaching, training, mentoring, and developing, plus reviewing, interviewing, staffing, and posting. People move around so frequently in the Red Cross delegations, some of them so widely, and stay for such short periods, that the need for this side of leadership seems to be almost insatiable-a problem increasingly encountered in more conventional organizations these days.

The chain of command from Geneva through Dar-esSalaam to N'gara appeared to be strong, down through which passed a great deal of procedure, established and reinforced by experience and packaged in a strong culture. That would seem to be the great strength of the Red Cross. But all this has to be delivered by its people, on whose shoulders all this succeeds or fails.

One could not but be impressed with their success at N'gara. Anyone who came to this operation with no idea what to expect had to leave not only impressed but also inspired. Yet concerns naturally arise as one begins to get a sense of the turnover of staff and the enormous amount of effort that has to be invested in training, and in dealing with the many problems that arise before such training is completed (if ever, in many cases), likewise until smooth teamwork is achieved (if ever, in most cases). Most remarkable here, then, was the rather steady state of the operations amidst the unsteady state of the staff! And that suggests the pre-eminence of controlling, over leading.

The chain in this organization appears to be strong, perhaps too strong. (Delayering seems hardly to have reached the Red Cross operations, not when one considers 
the spans of control, the presence of counterparts, and so on.) But the weak link is turnover, which necessitates all that training and much of that controlling.

A second aspect of leadership is culture building, or at least culture diffusion. Abbas, especially, was the carrier of the Red Cross culture in N'gara, both as head of delegation and as the person most steeped in the culture. Getting the other, newer delegates (many of them on outside contract to the Red Cross) to imbibe the culture is one key way to shortcut all the problems of turnover, etc. If a delegate is an expert already (as was Gier, for example, in health services), then it may be far more effective to get him or her believing in the Red Cross culture than understanding the Red Cross rules.

Abbas was raised in the Red Cross as a youth, and has been involved with it ever since. Part of his job in N'gara was to ensure that the Red Cross culture was reflected in whatever happened at his delegation, whether that was strict enforcement of the organization's neutrality or the simple fact of wearing bibs when distributing food on its behalf. Symbols matter, especially one as famous and potent as that of the Red Cross.

Another aspect of leadership concerns conflict resolution to ensure that people work together harmoniously. Again, there was no shortage of this in Abbas's day, and, again, for much the same reason. Many people had not been long in the job, so they were not used to working together. Add to this the mixture of cultures, nationalities, backgrounds, and languages, and conflicts abound-often just misunderstandings. Many seemed to find their way to Abbas. Of course, he was head of the unit there. But he could also speak English with the Europeans and then turn around and talk Swahili with the Tanzanians; likewise, he could switch easily between people of different origins, needs, and experiences, as became clear in how he worked his way through the matron's conflict.

Leadership activities were less in evidence in Stephen's day, perhaps partly because of the particular mix of activities this day - much time with Ben and in the campsand because of his shorter tenure in the job. Nonetheless, the leadership dimension of his walk through the camp should be noted here: Stephen was collecting information and looking for possible problems to be sure, but he was also showing the flag, so to speak. The importance of being there as a representative of the organization, especially in the charismatic way he did it, is not to be underestimated.

\section{Linking}

Linking with outside stakeholders may not have dominated these two days, but its importance was evident in both jobs. Stephen had his long meeting with Ben, and he connected laterally around the quadrangle and through the camps with all sorts of people; while Abbas had his contacts with various Tanzanian counterparts, with the NGO people, and with other Red Cross officials in Dares-Salaam and Nairobi as well as Geneva by mail and telephone. This was enough to suggest not only the criticality but also the intricacy of the linking role.

The various agencies in N'gara formed a complex web of relationships, shown in Figure 2. Some supplied others (as the UNWFP shipped food to the Red Cross for distribution and ECHO funded the Red Cross), while a number worked in parallel to serve the same beneficiaries in the camps (as in the provision of education). And then there were the many Tanzanian authorities present as well as the Tanzanian Red Cross Society, even the German Red Cross Society, which provided health care and water. Somehow, all this had to get coordinated, and the Red Cross seemed to play a key role-albeit informal-in accomplishing this, which involved more linking than leading, more convincing than controlling, more dealing then doing.

Linking means not only ensuring that influence flows out (as when Abbas had to speak to the UNWFP about delays in the receipt of the food), it also means dealing with the influence that flows back in, as when the refugees complained about the camp manager or when that TRCS official in Dar-es-Salaam announced the uninvited visit of that physician. Here, the manager had to walk a delicate line because letting in all the external influence could put enormous pressure on their people, while blocking it all out (extending the "compound" beyond its physical boundaries, so to speak) could disconnect them from the outside world and lead to worse problems. Another option, of course, especially on the part of conscientious managers, is to absorb much of this influence themselves. But in this context, that would only have speeded up the process of burnout. So managing here had to combine a

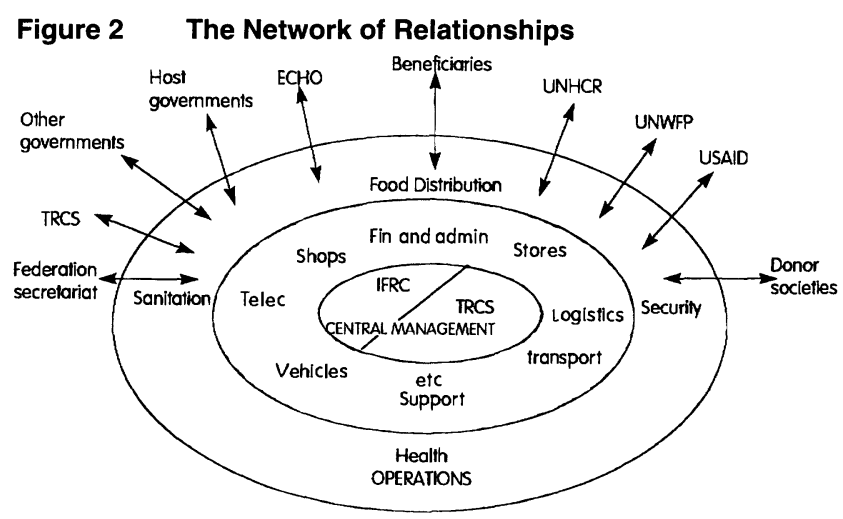


certain toughness with a certain sensitivity, best illustrated in Abbas's handling of the Matron's issue.

Mention should be made here again of Abbas's ability to bridge-not only between English and Swahili as well as between Africans and Europeans, but also between a head office in a wealthy European city and the site office in an impoverished African township. In sociological terms (Gouldner 1957), Abbas was a rare breed here: a cosmopolitan and a local. He was able to combine his formal knowledge of the institution with his tacit knowledge of the situation. This suggests that socialization must be critically important in the Red Cross, especially in its youth wing, where kids from Kenya or Canada can become more worldly without forgetting their roots, and so eventually take their place as bridges from the world of plenty to that of need.

\section{Doing and Dealing}

Doing is a bit of a misnomer in managerial work, since managers don't actually $d o$ very much of what their organizations get done. Rather, as the French put it, they "faire faire," literally to make it get made. To "do," then, really means to manage the taking of action more or less directly (as Stephen might have done if he stood over that fence and supervised its construction). Dealing is the equivalent outside the organization, such as in negotiating contracts or making arrangements with associates.

Neither of these jobs seemed to be primarily about doing or dealing. Yet both roles were in evidence during these two days, for example, when Abbas decided to handle himself the problem of the direct delivery of food to the chutes and to resolve the issue of the matrons, and when Stephen worked on the complaint about camp management. Immediacy seems to be critical.

Another side of managerial work in this context was revealed in a story Abbas told about an experience some months earlier, when a boat overturned on Lake Victoria, causing almost a thousand deaths. As soon as he heard the news, Abbas called the TRCS office in Dar-esSalaam. Realizing that they were unprepared for this, and being relatively close (many hours, nonetheless, over land), he took nine others-three delegates and six Tanzanians (including Stephen, the Assistant Matron trained as a psychiatric nurse, which is how Abbas came to know him so well). They grabbed what supplies they couldbody bags, stretchers, disinfectant, etc.-and headed there by road, arriving one day after the accident as the first NGO on site. The group stayed two solid weeks, working very long hours, arranging for body recovery, setting up a morgue in the nearest stadium (to which 40,000 people came the first day), and dealing with the bereaved families.
So there is important "doing" in this job, indeed it is the very essence of this job, but not in the steady state of N'gara during these two days of observation. Yet, ironically, the steady state of the relief operations of the Red Cross Federation overall is the management of crisis. And the success of these two managers was in their ability to reduce crisis to a state of the steady delivery of service.

It might be concluded then that the less "doing" by these managers, the clearer the indication that things are running smoothly. For they have to do, or deal, only when unexpected problems arise. That, of course, is why they spent so much effort getting themselves informed: to be able to catch such problems early, before they explode out of control, as they so easily can in such circumstances. The apparent calm and order in N'gara only camouflaged tremendous forces below the surface.

Yet, coming at the issue from the other side, neither job was really about strategy. They were about getting things done, largely through controlling and communicating, and, when necessary, doing. The Red Cross might thus be likened to a fire department, ready to move with well-defined procedures, but never sure when or where.

To conclude this review of the management roles, we find the different roles to be rather balanced in importance if not in actual attention. Communicating seemed to be of central concern in both jobs, although done differently, and controlling especially in Abbas's job. Leading was reflected especially in the training Abbas did, and linking was obviously critical to both jobs. On the action level, doing and dealing were also important, but in a sense represented as much by their absence as by their presence.

As conventional management theory might suggest, Abbas managed more from his office than did Stephen, exhibited more of a top-down deductive style, and got his information more verbally. His job could be described as more cerebral-certainly he was much more comfortable with office procedure-although the mixture of the formal with the informal, the analytical with the intuitive, and the cerebral with the insightful, seemed crucial to the conduct of both jobs. Management, as always, but so much more highlighted in a refugee camp, may have its artistic side and may make some use of science, but it is ultimately a craft.

\section{Conventional Management in an Unconventional Setting}

Mass production "machine bureaucracies" might be described as conventional organisations, and project oriented "adhocracies" as contemporary ones (Mintzberg 1979). Conventional management, in the former then, has been about controlling to maintain steady state, reinforced 
by so-called "management by exception," a term seldom found in the literature today. And contemporary management is about teamwork, facilitation, venturing, and so on.

In this regard, these were two days of rather conventional managing, old-fashioned practices if you like, fully compatible the ideas of Fayol (1949). Yet the context here was not conventional at all, not in its place, not in its pressures, not in its purpose. These two managers were there to reduce crisis to steady state, indeed to institute the mass delivery of services: They had to turn a wilderness of multitudes into what appeared to be a smoothly functioning city. At this they and their colleagues succeeded brilliantly. How many brand new cities of 175,000 people settle down so quickly?

Yet that remarkable steady state could only be temporary. Benaco and Lukole were, in a sense, projects; indeed, Abbas and Stephen were "delegates" to a temporary "delegation," in other words, an adhocracy, even though it had to function as if it were a machine bureaucracy. So here we have conventional management practiced in a most unconventional setting.

Indeed, it could be argued that it was the very unconventional nature of the setting that made the management so conventional. Because N'gara could blow at any time, from the least, or the least expected, of events, keeping a steady state had to become almost obsessional. Here were hundreds of thousands of displaced persons, having recently lived through (or created) horrendous experiences, all of them literally walking distance from repatriation and possible annihilation. (In fact, at this very time, the camps on the other side of these two borders, in Zaire, were in turmoil-under attack by rebels. A hospital at one camp, very much like the Gulf Hospital, had been infiltrated and all the patients as well as some of the Swedish nursing staff had been murdered.) So control, order, communication, and preparation for fast reaction became absolutely critical in this context of instability.

\section{Risks and Options}

So what are we to make of managers, of risks, and of options here? There is a great deal of discussion of risk in the management literature, but mostly it is about the risk of losing financial and material resources, usually by organizations that have a great deal of them to begin with. Risk here was about death, and massacre. Options has a rather narrow and technical meaning in finance but a much broader meaning in the work of Ned Bowman. The interesting thing about the context of N'gara is that there may not have been any real options, not if there was to have been a civilized and coordinated response to human tragedy. The Red Cross comes in for a certain amount of criticism in its work. If the circumstances of N'gara are any indication, it is to its great credit that there is not a great deal more.

As academics, we imagine that we exercise all kinds of options. In fact, we exercise few, since we so often restrict ourselves to rather conventional settings that we think of as contemporary. We take too few risks.

The study of Abbas and Stephen in N'gara is not presented as just another contribution to our stock of management concepts, although we hope we have added our share. It is presented in the hope that we can open up our thinking to new contexts-new places in the world as well as in our heads. Surprising insights can occur when new territory is explored, such as NGOs in Africa, to understand better the intricacies of alliances in business, to realize too that conventional forms of management may be contemporary in a chaotic world, indeed that the real chaos is happening, not in the comfortable offices of western corporations, but in places where the management literature rarely goes. N'gara is part of this "globe," too.

\section{Afterword}

On a Sunday afternoon in November of 1996, a little over a month after this visit, the Tanzanian government announced that all the Rawandan refugees had to be repatriated. In 10 days, the city of Benaco, with 175,000 people, no longer existed. No one was allowed into the camp except Red Cross officials, who found children and sick and elderly people left behind, as well as many dead bodies.

The refugees headed out of the camps, grabbing what they could carry, but going the other way, deeper into Tanzania, some as far as a hundred kilometers. The Tanzanian authorities gathered them up and sent them home. The line-up at one point was reported to be 60 kilometers long.

Abbas, who was supposed to have finished his mandate, stayed on site to try to deal with the resulting chaos, personally providing first aid and water, and assisting the helpless. When I reached him toward the end of this by satellite telephone, he was in a state of disbelief. "I'm a little bit tired," he said, only later admitting to being "physically and mentally worn out. I thought this would never happen," said the man who had seen just about everything. The camp that weeks earlier had been "thriving and full of life," was now "an empty ghost town."

This story is entitled "Managing Exceptionally" for three reasons. First, it is about the classic view of management by exception. Second, it is about managing in exceptional circumstances. And third, most importantly, 
it is about exceptional people in an exceptional institution, who dedicate themselves to making the world a better place. What brought them to N'gara is dreadfully sad; what they did there is wonderfully inspiring. As researchers, we would do well to honor the exceptional man to whom these articles are dedicated by taking more risks and paying more attention to our own options.

\section{Endnotes}

${ }^{1}$ For more information on the personal side of the compound and the camps, a short story is available from the author entitled " 'Depressing' is Hardly the Word."

\section{References}

Fayol, H. 1949. General and Industrial Management. Pitman, London. Goffman, E. 1961. The characteristics of total institutions. E. Etzioni,

Accepted by Arie Lewin. ed. Complex Organizations: A Sociological Reader. Holt, Rinehart \& Winston, New York. 312-340.

Gouldner, A. W. 1957. Cosmopolitians and locals: Toward an analysis of latent social roles. Admin. Sci. Quart. 281-306.

Mintzberg, H. 1973. The Nature of Managerial Work. Harper and Row, New York.

1979. The Structuring of Organizations. Prentice-Hall, Englewood Cliffs, N.J.

- 1991. Managerial work: Forty years later. Sune Carlson, ed. $E x$ ecutive Behavior. Textgruppen I, Uppsala, Sweden.

- 1994. Rounding out the manager's job. Sloan Management Rev. (Fall) 11-26.

1996. Managing government, governing management. Harvard Bus. Rev. (May-June) 75-83.

Peters, P. J., R. H. Waterman. 1982. In Search of Excellence. Harper and Row, New York.

Weick, K. E. 1974. Amendments to organizational theorizing. Acad. Management J. 17(3) 487-502. 